\title{
Functional Polymer Nanocomposite Materials from Microfibrillated Cellulose
}

\author{
Philippe Tingaut, Christian Eyholzer and Tanja Zimmermann \\ Swiss Federal Laboratories for Materials Science and Technology (EMPA) \\ Switzerland
}

\section{Introduction}

In line with recent environmental policies, increased attention has been paid to the development of bio-based nanocomposite materials for several industrial applications, such as automotive, construction, packaging or medical applications. Thus, much effort has been devoted to the use of natural fibers in composite materials as an alternative to conventional inorganic fillers, traditionally used to reinforce thermoplastic matrices (i.e., glass fibers, aramid or carbon fibers, for instance).(Eichhorn, 2006; Pandey, et al., 2005) Hence, natural fibers present very attractive properties such as low cost, renewability, biodegradability and low density.(Bledzki \& Gassan, 1999; Samir, et al., 2005)

Cellulose is the most abundant biopolymer on earth, and is present in natural fibers such as wood, cotton or hemp, as well as in a wide variety of living species, such as animals, plants and bacteria. This linear polymer is composed of $\beta-1,4$ linked glucopyranose units, with polymer chains associated by hydrogen bonds forming bundles of fibrils, also called microfibrillar aggregates, where highly ordered regions (i.e., crystalline phases) alternate with disordered domains (i.e., amorphous phases).(Samir, Alloin \& Dufresne, 2005) In the last decades, the production of cellulose nanofibers from different sources has gained a tremendous success. Hence, apart from the already mentioned advantages related to natural fibers, cellulosic nanoelements also possess very high strength and stiffness, therefore making them excellent reinforcing agents for nanocomposites. As will be discussed later in detail, two main types of cellulose nanofibers can be produced: the Cellulose nanowhiskers (CNW) and Microfibrillated cellulose (MFC). These natural fillers differ from their size and crystallinity, but the highest aspect ratios are usually found for MFC.

In the past decade, the EMPA Wood Laboratory has acquired a strong experience in the production, functionalization and use of MFC for a wide range of applications, including adhesives, packaging or medical applications. Consequently, this book chapter will specifically address the elaboration of functional nanocomposite materials using MFC as reinforcing agent. A first section will present the production and properties of MFC. In a second section, the chemical modification of MFC will be presented, therefore highlighting the possibility to tailor the surface polarity of the cellulosic fillers. Finally, a third section will address the elaboration of nanocomposite materials from unmodified and functionalized MFC. 


\section{Cellulose nanofibers}

As stated in the Introduction part, cellulosic nanoelements are mainly divided into two main families, which are the CNW and MFC. We will thus present these nanofibers in terms of preparation and morphological properties, with an emphasis on MFC.

\subsection{Cellulose Nanowhiskers (CNW)}

CNW, also called cellulose nanocrystals, are usually isolated from cellulose fibers through an acid treatment. This simple process involves an acid hydrolysis of the biomass using concentrated sulfuric acid $\left(\mathrm{H}_{2} \mathrm{SO}_{4}\right)$, which removes disordered or paracrystalline regions of cellulose and leaves crystalline regions intact. After this treatment, cellulose nanocrystals with a rod-like morphology are produced. The geometrical dimensions of these nanoparticles depend on the starting cellulose source, resulting in CNW with widths in the nanometer scale and lengths from nanometer to micrometer scale. An example of CNW isolated from Microcrystalline Cellulose is presented in Fig. 1.

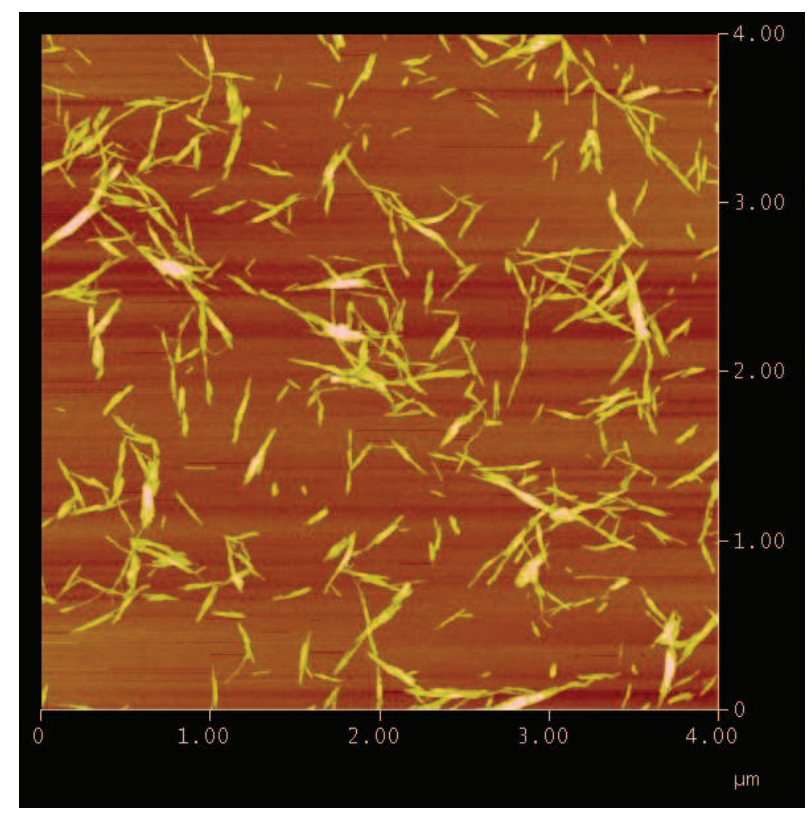

Fig. 1. AFM image of CNW

\subsection{Microfibrillated Cellulose (MFC)}

As compared with CNW, MFC consists of long, flexible and entangled cellulose nanofibers. MFC can be prepared from different raw materials and preparation processes, the characteristics of the resulting nanofibers being dependant on these two parameters. Wood constitutes the most important source of cellulose nanofibers, however research on other potentially suitable cellulose-based materials is in progress, especially in developing countries where agricultural wastes are underutilized. For this reason, cellulose sources coming from agricultural by-products have already successfully been tested for the 
production of MFC, such as wheat straw, sugar beat pulp, potato pulp or bagasse.(Siro \& Plackett, 2010)

Concerning the production of MFC, several mechanical treatments have been used, such as a two-steps process including a refining and a high-pressure homogenization steps, cryocrushing, and grinding methods. Developed in 1983 by Turbak et al., the homogenization technology allows the production of a network of interconnected cellulose microfibrils, with diameters from 10 to $100 \mathrm{~nm}$ and aspect ratios from 50 to 100.(Boldizar, et al., 1987; Gardner, et al., 2008; Turbak, et al., 1983; Zimmermann, et al., 2004) Without any cellulose pre-treatment, the two-steps mechanical process has usually led to the obtention of MFC with the smallest diameters.(Zimmermann, Pöhler \& Geiger, 2004) Nevertheless, in order to decrease the high energy consumption associated with such processes, chemical (Habibi, et al., 2006; Iwamoto, et al., 2007; Lasseuguette, et al., 2008) and enzymatic (Henriksson \& Berglund, 2007; Janardhnan \& Sain, 2006; Paakko, et al., 2007) pre-treatments together with subsequent mechanical processes have also led to the preparation of cellulose nanofibers with diameters between 5 and $30 \mathrm{~nm}$. In the EMPA Wood laboratory, MFC is obtained from cellulose fibers after a two-step mechanical disintegration process, consisting of an initial refining step followed by a high pressure homogenization step. Fig. 2 presents an example of MFC isolated from oat straw cellulose powder in our laboratory.

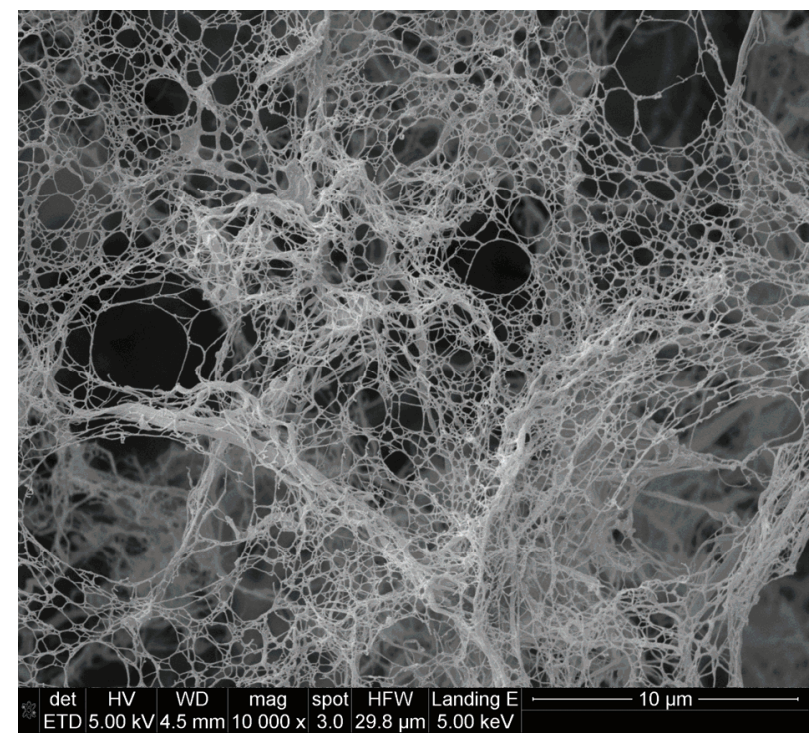

Fig. 2. SEM image of MFC mechanically isolated from oat straw cellulose powder

\section{Limitations of MFC in composite applications}

Nevertheless, despite all previously stated advantages, MFC suffers from its strong hydrophilic character which causes two critical issues, namely the hornification during drying and agglomeration of MFC in non-polar matrices during compounding.

Irreversible agglomeration of cellulose during drying is called hornification and is explained by the formation of additional hydrogen bonds between amorphous parts of the cellulose 
fibrils during drying. (Young 1994; Hult et al. 2001) The formation of these bonds is related to the amount of water removed, and does not depend directly on temperature. As in the crystalline parts of cellulose, water cannot break the formed hydrogen bonds of hornificated cellulose during rewetting.(Eyholzer, et al., 2010a) For this reason, isolation of MFC is preferentially done by mechanical disintegration of never dried pulp in aqueous suspension of low cellulose concentration ( 1 to $2 \% \mathrm{w} / \mathrm{w})$. The consequences are high storage volumes and shipping costs, as well as a decrease in storage life of the product due to bacterial degradation.

Moreover, in order to match the targeted property improvements, the natural fibers must be homogeneously dispersed in the polymeric matrix, which is non-trivial. Hence, due to its strong hydrophilic character and high aspect ratio, MFC tends to flocculate through hydrogen bonding. In general, the dispersion of hydrophilic MFC in apolar solvents, as well as its further homogeneous incorporation in most common apolar thermoplastic polymers, is challenging. A non homogeneous dispersion of the filler in the polymer matrix is often obtained, thus decreasing the final mechanical properties of the nanocomposite material.(Hubbe, et al., 2008) For these reasons, the preparation of nanocomposite materials from MFC has often been restricted to water soluble polymers,(Dufresne \& Vignon, 1998; Lu, et al., 2008b; Zimmermann, Pöhler \& Geiger, 2004; Zimmermann, Pöhler \& Schwaller, 2005) latexes,(Samir, et al., 2004) acrylic and phenol-formaldehyde resin through a fiber impregnation process,(Iwamoto, Nakagaito \& Yano, 2007; Nakagaito \& Yano, 2008; Nakagaito \& Yano, 2004; Nakagaito \& Yano, 2005), or poly(lactic acid) under specific compounding conditions.(Iwatake, et al., 2008; Nakagaito, et al., 2009; Suryanegara, et al., 2009) As compared with neat matrices, the incorporation of MFC led to an increase in mechanical properties such as bending and tensile strength,(Iwatake, Nogi \& Yano, 2008; Nakagaito, Fujimura, Sakai, Hama \& Yano, 2009; Nakagaito \& Yano, 2004; Suryanegara, Nakagaito \& Yano, 2009; Zimmermann, Pöhler \& Geiger, 2004) Young's modulus,(Iwatake, Nogi \& Yano, 2008; Nakagaito \& Yano, 2008; Nakagaito \& Yano, 2005; Zimmermann, Pöhler \& Geiger, 2004; Zimmermann, Pöhler \& Schwaller, 2005), as well as thermal stability.(Dufresne \& Vignon, 1998; Iwatake, Nogi \& Yano, 2008; Lu, Wang \& Drzal, 2008b; Nakagaito, Fujimura, Sakai, Hama \& Yano, 2009; Samir, Alloin, Paillet \& Dufresne, 2004; Suryanegara, Nakagaito \& Yano, 2009) Moreover, recent studies have highlighted the possibility to prepare optically transparent nanocomposites by impregnating MFC with an acrylic resin.(Iwamoto, Nakagaito \& Yano, 2007)

Nevertheless, the hydrophilic character of MFC constitutes a major obstacle for its use in composite applications. In order to tackle this problem, one strategy involves the chemical modification of MFC's surface hydroxyl groups, in order to prevent hornification phenomena and/or decrease the nanofiber surface hydrophilicity.

\section{Chemical modification of MFC}

In the past decades, the chemical modification of MFC has received a significant interest from the scientific community. Thus, many reactions have already been performed in order to permanently modify the surface properties of the nanofibers (i.e., surface polarity), involving the use of the TEMPO oxidative agent,(Lasseuguette, Roux \& Nishiyama, 2008; Saito, et al., 2006) silane reagents,(Andresen, et al., 2006; Gousse, et al., 2004; Gousse, et al., 2002; Grunert \& Winter, 2002; Lu, et al., 2008a) isocyanates,(Nair, et al., 2003; Siqueira, et al., 2009) poly(E-caprolactone),(Habibi \& Dufresne, 2008) or anhydrides.(Cavaille, et al., 1997; 
Ifuku, et al., 2007; Kim, et al., 2002; Nogi, et al., 2006; Sassi \& Chanzy, 1995; Stenstad, et al., 2008)

In our laboratory, we have been particularly interested in developing simple and efficient modification pathways that could be potentially suitable for the modification of MFC at industrial scale. In this section, we will present two examples of chemical modifications which were envisaged to improve the nanofibers' properties in polar and non polar environments.

\subsection{Carboxymethylation of MFC}

Partial carboxymethylation of the MFC hydroxyl groups has been envisaged to overcome hornification during drying, with the aim to prepare dry, water-redispersible MFC (Fig. 3).

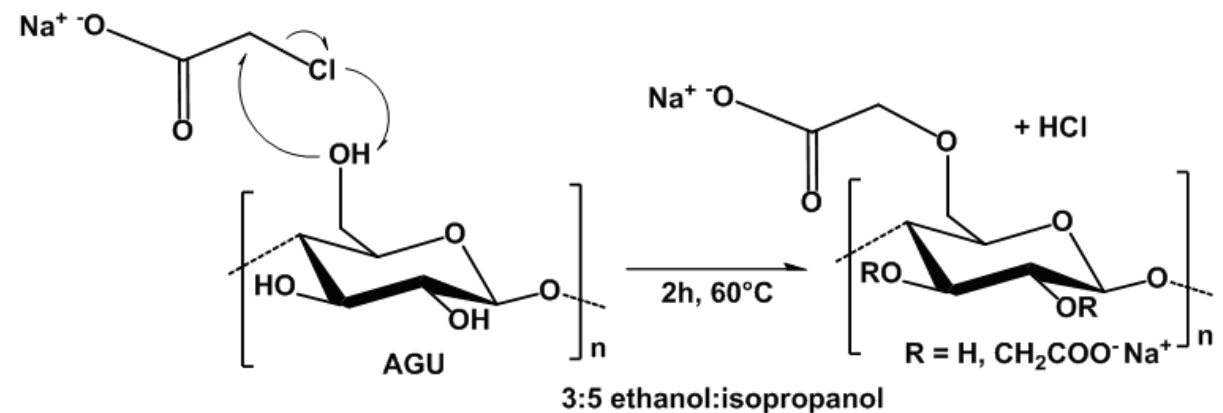

Fig. 3. Carboxymethylation of MFC

The success of the reaction was monitored using different characterization techniques, such as Fourier-Transformed Infrared Spectroscopy (FTIR) and Solid-State NMR spectroscopy. Finally, the impact of the modification on the properties of the modified MFC was evaluated, such as redispersion properties in water and crystallinity.

Two sets of experiments were compared. Unmodified and chemically modified MFC were dried to a powder from an aqueous suspension, and then redispersed in water. Finally, a drop of these suspensions was freeze-dried and the morphology of the resulting nanofibers was assessed using Scanning Electron Microscopy (SEM). Fig. 4 presents the crystallinity values, SEM and redispersion test images of these two samples. Results indicated that the crystalline structure of MFC was partially affected by the treatment, but a crystallinity of $49 \%$ could still be remained. But most importantly, differences were noted concerning the dispersion properties and morphology of these two samples. After $1 \mathrm{~h}$, a complete sedimentation of the unmodified MFC was observed, and the SEM characterization revealed large aggregates which were not dispersed in the suspension. These results confirmed the hornification problem of unmodified MFC. On the other hand, a stable and transparent suspension was obtained for the carboxymethylated MFC, a network of nanofibers with overall diameters below $100 \mathrm{~nm}$ being observed by SEM after freeze drying. Moreover, by varying the Degree of Substitution (DS), other morphological and dispersion properties of MFC could be obtained (not shown here).

In conclusion, these results confirmed the possibility to prepare dry, redispersable MFC with the carboxymethylation reaction, which is strongly interesting for composite applications. 


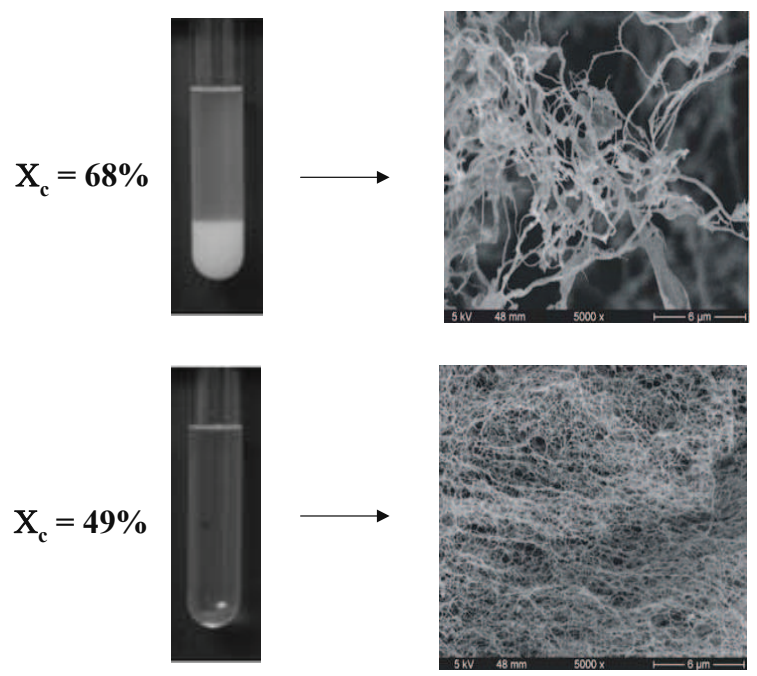

Fig. 4. Crystallinity $\left(X_{c}\right)$, redispersion tests in water $(0.2 \% \mathrm{w} / \mathrm{w}, 1 \mathrm{~h})$ and SEM images of unmodified and carboxymethylated MFC

\subsection{Acetylation of MFC}

In another approach, the acetylation of MFC has been envisaged to decrease the nanofibers hydrophilicity, and further improve the chemical affinity between MFC and non-polar environments (Fig. 5).<smiles>CC(=O)OC(C)=O</smiles>

Fig. 5. Chemical modification of MFC with Acetic Anhydride

The acetylation reaction has been monitored spectroscopically, and the kinetics of the reaction was obtained by plotting the evolution of the DS against reaction time (Figure 6). As shown in this graph, the DS increased rapidly during the first $60 \mathrm{~min}$, suggesting that the reaction occurred primarily on easily accessible surface hydroxyl groups $(\mathrm{OH})$. On the other hand, the reaction rate gradually slowed down up to $180 \mathrm{~min}$, with DS ranging from 0.37 to 0.41. This behavior was associated with the modification of less accessible surface $\mathrm{OH}$ groups which may be located deeper in the nanofibers, as well as steric hindrance induced by grafted acetyl groups on fiber surfaces, thus affecting the reaction rate.

In parallel, the dispersion properties of unmodified and acetylated MFC were examined in $\mathrm{CHCl}_{3}$, a solvent of low polarity (Fig. 6). All nanofibers were first manually dried to a powder form and redispersed afterwards in $\mathrm{CHCl}_{3}$. Unmodified MFC could not be dispersed, as a result of strong hornification during drying. However, the suspensions of 
acetylated MFC showed varying degrees of stability, which were dependent on DS. Stable suspensions were observed for acetylated MFC with a DS above 0.18, the suspensions being increasingly homogeneous with the modification rate. This behavior was associated with the increasing amount of acetyl moieties on the cellulose surface, thus limiting the interactions between adjacent microfibrils. However, a total flocculation was observed for MFC with a DS of 0.13 , which was associated with an incomplete acetylation of the nanofibers surface. These innovative results confirm that the acetyl groups prevent the interactions between nanofibers, and suggest that a minimum DS is required to efficiently disperse dried $\mathrm{MFC}$ in $\mathrm{CHCl}_{3}$. This finding is of great interest from an economical point of view, as the acetylation treatment would also provide powdered MFC, reducing significantly the transportation costs.

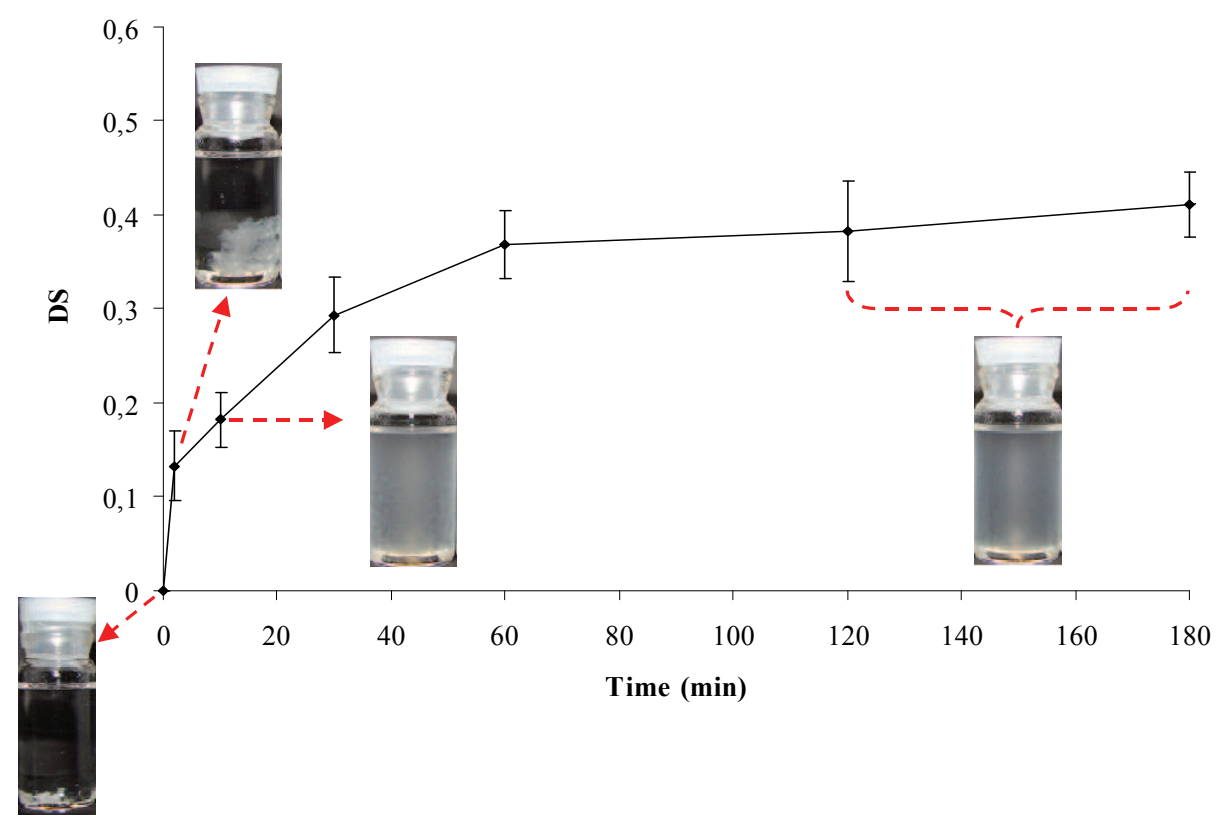

Fig. 6. Evolution of DS as function of reaction time. Photographs indicated by red arrows display the stability of the suspension in $\mathrm{CHCl}_{3}$

\section{Elaboration of nanocomposites from MFC}

As stated in the previous sections, our activities in the EMPA Wood Laboratory have been dealing with the reinforcement of polar and non polar polymer matrices for many applications. In this section, examples of nanocomposites reinforced with unmodified and chemically modified MFC will be presented, and the envisaged applications of the resulting nanocomposites will be addressed for all of them. Two polymer matrices were envisaged, namely the hydrophilic Hydroxypropyl Cellulose (HPC) and the hydrophobic Poly(lactic acid) polymers. Unmodified and functionalized MFC were both used as reinforcing agents, and the impact of the modification on the resulting composite properties was evaluated. All nanocomposite films were prepared using a solvent casting approach, a simple and efficient method commonly used at laboratory scale for the preparation of composite materials. 


\subsection{HPC nanocomposites}

HPC is a highly interesting cellulose derivative which has been extensively analyzed, regarding its ability to form liquid crystalline (LC) mesophases (Werbowyj \& Gray, 1976; Werbowyj \& Gray, 1980) and its compatibility with cellulosic nanofibers.(Johnson, et al., 2009; Zimmermann, Pöhler \& Geiger, 2004). Therefore, we envisaged to reinforce HPC using unmodified and carboxymethylated MFC, and we studied the impact of drying these nanofibers on their reinforcing potentials in HPC composites.(Eyholzer, et al., 2010b) The carboxymethylated nanofibers being not susceptible to hornification problems, the preservation of their ability to reinforce matrices in powder form would be highly beneficial from a practical and industrial point of view.

The polymer matrix was reinforced with either never-dried (aq) or dried and redispersed (s) nanofibers. All composite films had a filler content of $20 \%(\mathrm{w} / \mathrm{w})$ and were characterized by dynamic mechanical analysis (DMA). The viscoelastic responses of all composites studied are presented in Fig. 7.
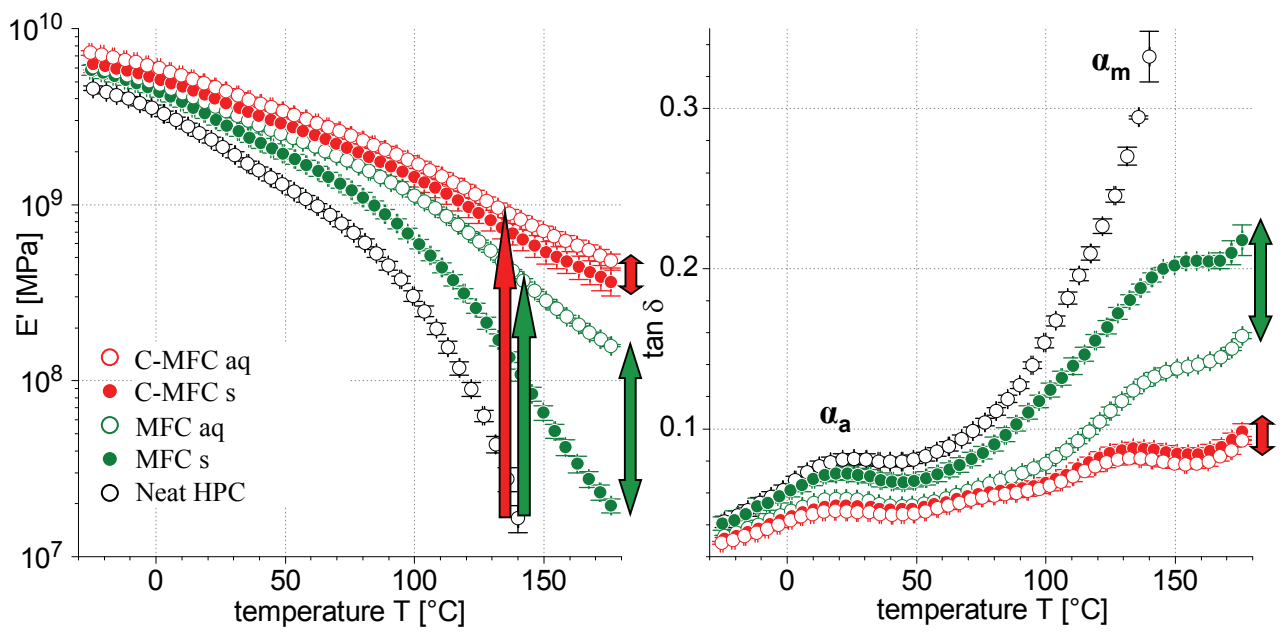

Fig. 7. Temperature dependence of the Storage modulus ( $\left.E^{\prime}\right)$ (left) and $\tan \delta$ (right) for neat HPC (black) and its nanocomposites reinforced with $20 \%(\mathrm{w} / \mathrm{w})$ of unmodified (green) and carboxymethylated (red) MFC. (aq: never-dried, s: dried and redispersed)

\subsubsection{Neat HPC}

The neat HPC films (black) show three regions that are separated by two relaxations, $\alpha$ a and $\alpha \mathrm{m}$, both involving large-scale molecular motions. (Pizzoli, et al., 1991) In the first region ranging from -30 to $20^{\circ} \mathrm{C}$, the films exhibit a very high storage modulus which is in the range of several GPa. At these temperatures, the bulk HPC consists of essentially three distinct phases: a crystalline phase, a disordered isotropic amorphous phase and a phase of intermediate order which was described as a frozen anisotropic amorphous phase.(Pizzoli, Scandola \& Ceccorulli, 1991; Rials \& Glasser, 1988; Wojciechowski, 2000) At $20{ }^{\circ} \mathrm{C}$, a first transition can be observed, indicated by the peak in the $\tan \delta$ curve. This Tg-like transition was attributed to the $\alpha$ a relaxation, denoting a devitrification process of the disordered amorphous phase. The second region between 20 and $130^{\circ} \mathrm{C}$ is characterized by a relatively 
large drop in storage modulus, exhibiting a remarkable softening of the films. Around 130 ${ }^{\circ} \mathrm{C}$ a second $\mathrm{Tg}$-like transition occurs with a strong increase in the $\tan \delta$ intensity, known as the $\alpha \mathrm{m}$ relaxation. (Pizzoli, Scandola \& Ceccorulli, 1991) In the third region above $130{ }^{\circ} \mathrm{C}$, the storage modulus decreases drastically and the neat HPC films start to flow. At these temperatures, the flexible side chains of HPC act like an internal plasticizer, allowing the rather stiff main chains some mobility. To avoid plastic deformation of the neat HPC films in tensile geometry, we limited data acquisition to $140{ }^{\circ} \mathrm{C}$ for this reference sample.

\subsubsection{Viscoelastic properties of composites reinforced with never-dried (aq) and dried and redispersed $(\mathbf{s})$ nanofibers}

To allow easier comparison, green and red curves denote composites reinforced with unmodified and carboxymethylated MFC, respectively. Open and filled circles correspond to nanocomposites reinforced with never-dried (aq) and dried and redispersed (s) MFC.

For all composites studied, the storage modulus of the composite films increased with fiber loadings regardless of the treatment. Below the $\alpha$ a relaxation at $-20{ }^{\circ} \mathrm{C}$, the increase in storage modulus was generally small. At $75^{\circ} \mathrm{C}$, after the $\alpha$ a relaxation, this increase became more pronounced. However, the strongest increase in $\mathrm{E}^{\prime}$ compared with neat HPC was observed at $140{ }^{\circ} \mathrm{C}$, after the $\alpha \mathrm{m}$ relaxation. This later increase in storage modulus was associated with the formation of a highly rigid percolating network of fibrils.(Dalmas, et al., 2007) The rigidity of this network arises from strong hydrogen bonds and entanglements between the fibrils. Clearly, the tan $\delta$ intensity of all composites was reduced over the whole temperature range but most pronounced in the high temperature region above $130{ }^{\circ} \mathrm{C}$. This decrease in $\tan \delta$ is commonly associated with the increased volume fraction of the filler in the composites. However, it can be observed that the decrease in $\tan \delta$ intensity depends on the filler type, becoming more pronounced for the functionalized MFC. This suggests that the presence of the fillers, together with the resulting percolating networks, promoted different degrees of segmental restrictions of the molecular motion of HPC chains, leading to an increase in $E^{\prime}$ and a decrease in $\tan \delta$. The efficiency of these segmental restrictions may depend on surface chemistry (i.e. the availability of carboxylate groups COO-), surface area to volume ratio and aspect ratio of the filler.(Johnson, Zink-Sharp, Renneckar \& Glasser, 2009) As carboxymethylation prior to mechanical disintegration enhances the isolation of fibrils,(Eyholzer, Bordeanu, Lopez-Suevos, Rentsch, Zimmermann \& Oksman, 2010a) this might lead to the production of fibrils which are favorable in terms of the above mentioned properties compared to unmodified nanofibers, and therefore account for more efficient segmental restriction of HPC molecular motion.

Nevertheless, a clear difference was observed between the films containing unmodified and carboxymethylated MFC. For all temperatures studied, storage modulus values of HPC reinforced with dried and redispersed (s) unmodified MFC were clearly lower than its never-dried analogues. This effect can be attributed to the hornification of MFC upon drying as described earlier, leading to a reduction of the fiber's aspect ratio and the prevention of a percolating network formation. In contrast, films containing dried and redispersed carboxymethylated MFC showed an almost identical response as those containing the never-dried fibers in the whole temperature range.

In conclusion, carboxymethylated MFC can be dried and redispersed in water without affecting its mechanical performance in nanocomposite applications. 


\subsection{PLA nanocomposites}

Polylactic acid (PLA) is a hydrophobic biopolymer, soluble in chloroform, and is considered biodegradable and biocompostable. This thermoplastic polymer can be synthesized from natural resources (e.g. starch or corn) and shows high strength and stiffness. Therefore, PLA has gained strong interests in several fields of applications, such as food packaging, automotive or medicine.(Garlotta, 2001) Its reinforcement with natural fibers has already been reported in literature, but few studies report the use of cellulose nanofibers, such as MFC as filler reinforcement in PLA matrices. Moreover, the same limitations have often been pointed out, such as aggregation of the filler and a lack of compatibility at the fibermatrix interface.(Iwatake, Nogi \& Yano, 2008; Mathew, et al., 2005)

In this context, we proposed to reinforce PLA with acetylated MFC, as it was shown earlier that such nanofibers display excellent dispersion properties in $\mathrm{CHCl}_{3}$, a PLA solvent.(Tingaut, et al., 2010) In addition to an improved filler dispersion as compared with unmodified MFC, an improved fiber/matrix interface was therefore expected due to the grafting of hydrophobic acetyl moieties on the surface of the nanofibers. PLA bionanocomposites with tunable properties were prepared using unmodified and acetylated MFC (with DS ranging from 0 to 0.77 ), with MFC contents from 2.5 to $17 \mathrm{wt} \%$. The resulting nanocomposites were characterized in terms of filler dispersion and mechanical properties. The quality of filler dispersion in the PLA matrix was visually evaluated assessing the transparency of the resulting films. Similar differences were observed among all filler contents tested, and therefore only photographs corresponding to nanocomposites reinforced with $10 \mathrm{wt} \%$ MFC are presented in Fig. 8. As compared with the neat PLA film, nanocomposite films were less translucent, but different behaviors were obtained depending on the DS. The addition of unmodified MFC led to a film off-white in color, with the appearance of MFC aggregates as white dots all over the film. When acetylated MFC was used, the presence of aggregates progressively vanished with an increase in DS, and the films became increasingly translucent. These observations suggest that the MFC dispersion in the PLA film was significantly improved by the surface grafting of acetate groups, and correlate with the improved dispersion of acetylated $\mathrm{MFC}$ in $\mathrm{CHCl}_{3}$.

The mechanical properties of the composites were evaluated using tensile tests measurements (Fig. 9). As it can be seen, in general, the presence of the MFC had a strong

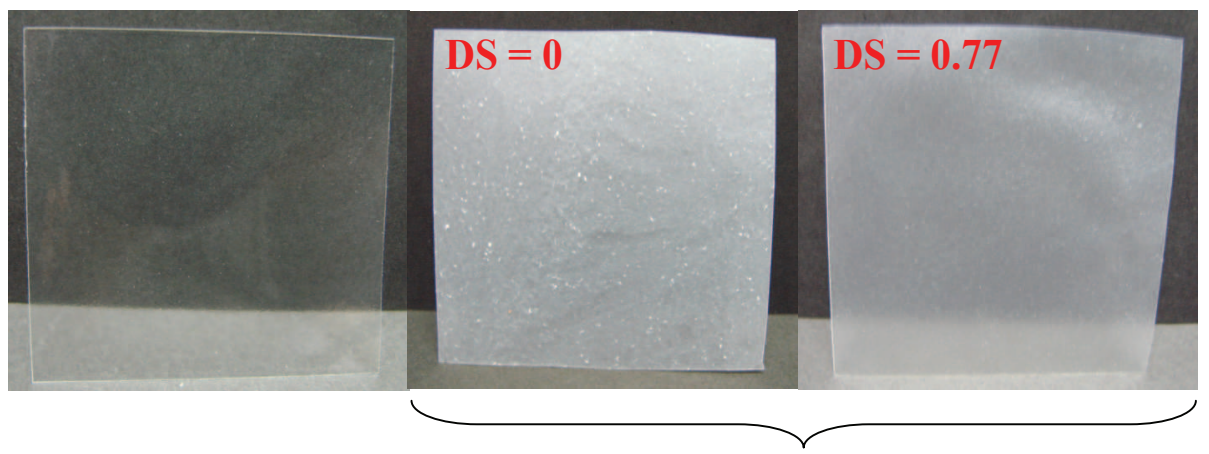

PLA

PLA $+10 \%$ MFC

Fig. 8. Optical micrographs of neat PLA and its nanocomposites reinforced with $10 \%(w / w)$ of unmodified and acetylated MFC 
Young's modulus (MPa)

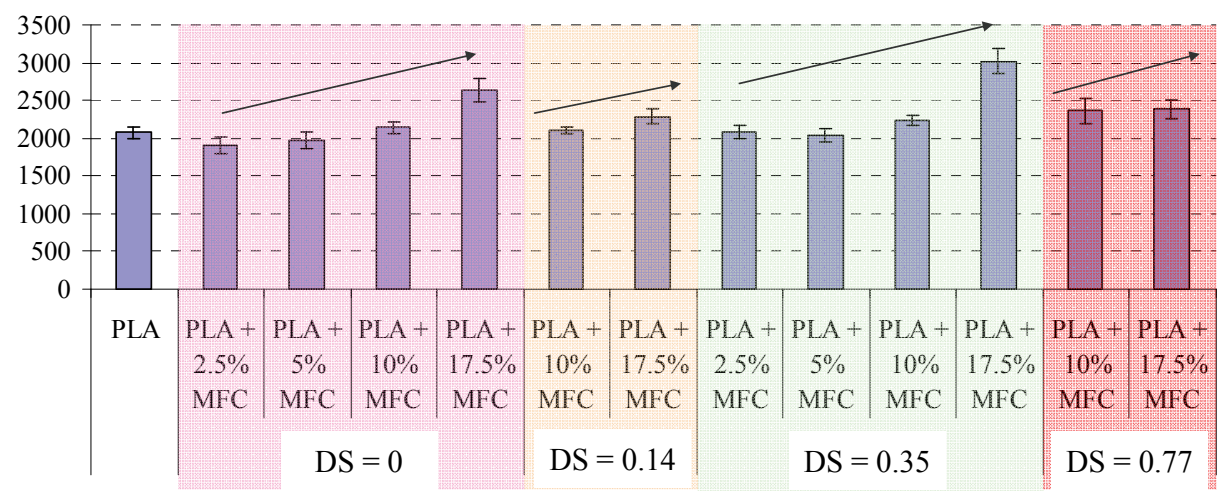

Tensile strength $(\mathrm{MPa})$

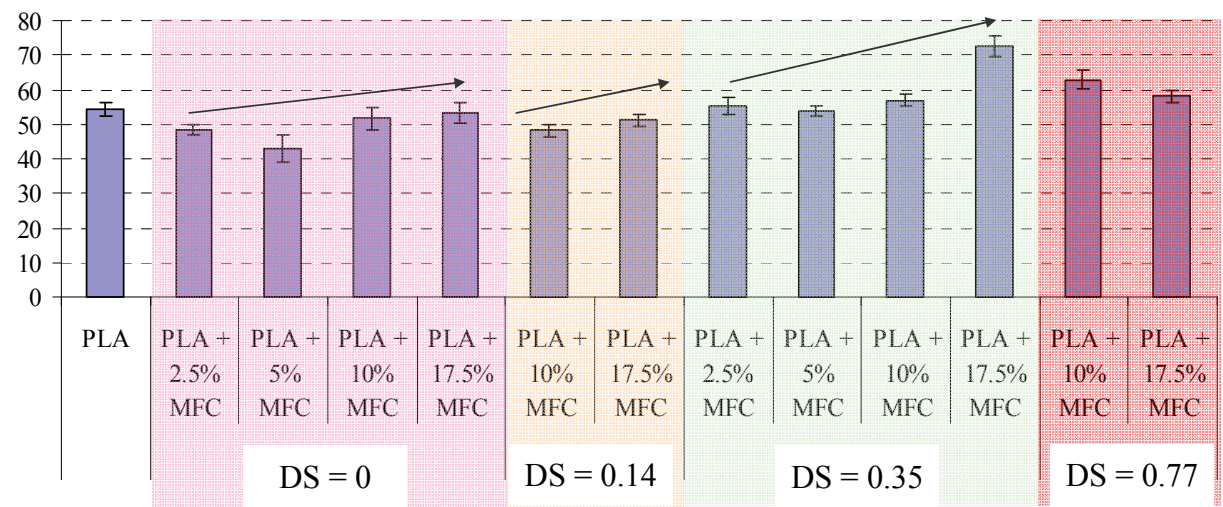

Strain at break $(\%)$

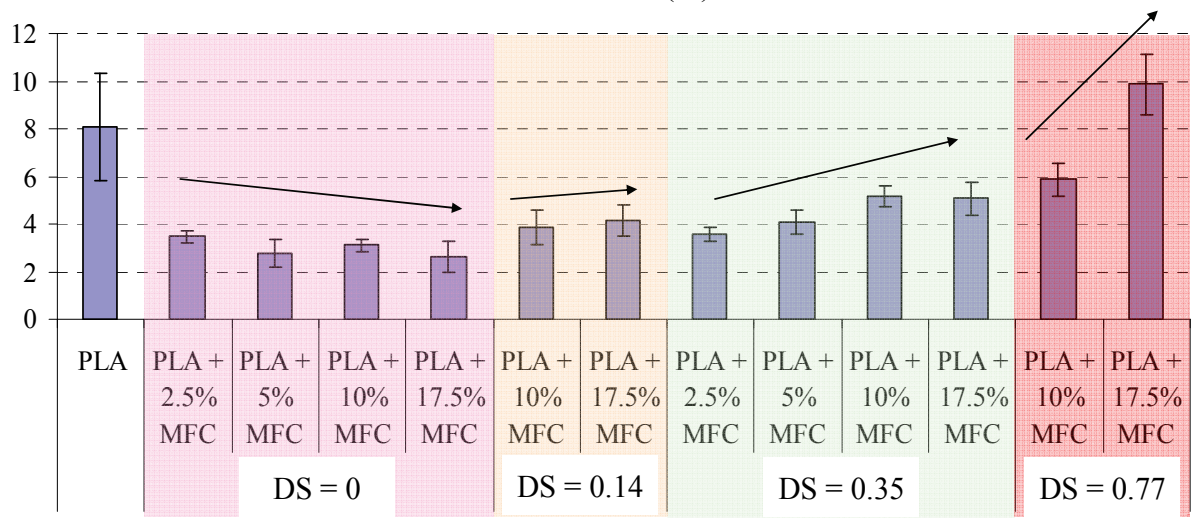

Fig. 9. Evolution of the Modulus of Elasticity (Young's modulus), Tensile strength and Strain at break as function of MFC content and DS 
influence on the Modulus of elasticity $\left(E^{\prime}\right)$, Tensile strength $(\sigma)$ and Strain at break $(\varepsilon)$ of the resulting nanocomposites.

As compared with neat PLA, a gradual increase in $\mathrm{E}^{\prime}$ and $\sigma$ was noted upon the incorporation of nanofibers, whatever the type of fibrils used. This reinforcing effect might result from the formation of a stiff hydrogen bonded cellulose network above a percolation threshold.(Dufresne \& Vignon, 1998; Siqueira, Bras \& Dufresne, 2009) But most interestingly, the DS significantly altered the reinforcement of nanocomposites. Hence, at the same filler content, higher $E^{\prime}$ and $\sigma$ were systematically measured for nanocomposites reinforced with nanofibers with a DS of 0.35 . This behavior was attributed to an improved dispersion and/or compatibility between the bulk PLA and the modified MFC at this particular modification rate, and suggests that an optimum DS is required to elaborate nanocomposite materials with higher mechanical properties. Surprisingly, nanocomposites reinforced with MFC having a DS of 0.77 did not present the highest mechanical properties, for which the best chemical affinity towards the hydrophobic PLA matrix would be expected. These findings suggest that a combination of the DS, which will adjust the chemical affinity of the microfibrils to the matrix, and the filler content are essential in order to achieve a good polymer-matrix interaction.

Finally, the DS seemed to have a strong influence on $\varepsilon$. As compared with neat PLA, a progressive decrease in $\varepsilon$ was measured upon filler content for nanocomposites reinforced with unmodified MFC, as expected. These results are in agreement with the increased stiffness of the materials with the MFC content. However, different results were obtained when acetylated MFC was used. Hence, $\varepsilon$ progressively increased not only with the filler content, but also with the DS of the nanofibers. These results might be associated with a disruption of the fiber network upon the introduction of acetyl moieties on MFC, therefore increasing the strain at break of the materials. However, additional experiments are needed to validate this hypothesis.

In conclusion, PLA bionanocomposite materials with enhanced properties (i.e., transparency, mechanical properties) were obtained as compared with those reinforced with unmodified MFC. Other properties could also be improved with the acetylated nanofibers, such as the hygroscopicity and thermal stability (not shown here). But most importantly, all these properties could be tailored by adjusting both the DS and the amount of MFC.

\section{Conclusion}

As demonstrated across this book chapter, Microfibrillated cellulose (MFC) is an excellent candidate for composite applications. Nevertheless, this highly promising natural material also suffers from its strong hydrophilic character, therefore leading to few drawbacks, namely the hornification phenomena upon drying, high shipping cost, susceptibility to biodegradation, as well as the lack of compatibility with non polar matrices.

We have here demonstrated that all these issues could be easily tackled through a chemical approach. Hence, the chemical modification of the cellulose hydroxyl groups clearly highlighted the possibility to use MFC in both dry or wet forms in composite applications, whatever the polarity of the matrix.

In aqueous environments, bionanocomposites from hydroxypropyl cellulose (HPC) with dried and redispersed carboxymethylated MFC powders were prepared. In general, the mechanical response of these composites was independent of whether the fibrils were dried 
or not prior to compounding. On the other hand, MFC without carboxylate groups showed a strong decrease of its reinforcing potential when dried before mixing with HPC due to hornification. In conclusion, these results demonstrated that carboxymethylated MFC in powder form has a high potential for polymer reinforcement with increased shelf life and easier handling compared to conventional MFC.

In hydrophobic environments, novel bionanocomposites were synthesized from PLA and acetylated MFC, with the objective of demonstrating that the final nanocomposite properties could be tailored through a careful control of the DS. It was shown that a DS above 0.18 prevented hornication upon drying. This was possible since the grafted acetyl groups allowed reduced hydrogen bonding between cellulose microfibrils. Moreover, we demonstrated that the resulting powdered nanofibers were easily redispersed in chloroform, a PLA solvent of low polarity, leading to very stable suspensions. These nanofibers were used to reinforce PLA through a solvent casting approach in chloroform. We showed that MFC with increasing DS provided more translucent nanocomposites versus unmodified MFC. Concerning the mechanical properties, regardless of the microfibril type, increasing amounts of MFC provided higher modulus of elasticity ( $\left.\mathrm{E}^{\prime}\right)$ and Tensile strength $(\sigma)$. However and most interestingly, higher $E^{\prime}$ and $\sigma$ values were measured for nanocomposites reinforced with acetylated MFC as compared with those reinforced with unmodified nanofibers, which was associated with an improved dispersion and/or compatibility at the fiber/matrix interface. We conclude that the possibility to redisperse dried acetylated MFC in a non polar solvent, such as chloroform, is very promising from an economical point of view, and opens up new opportunities for the development of novel nanocomposites materials using non polar matrices.

Thus, the chemical modification of MFC with simple and efficient methods constitutes a great industrial interest because the modified nanofibers can be stored in dry form, improving their durability against bacteria and reducing transportation costs.

\section{References}

Andresen, M., Johansson, L. S., Tanem, B. S. \& Stenius, P. (2006). Properties and characterization of hydrophobized microfibrillated cellulose. Cellulose, 13, 6, 665677.

Bledzki, A. K. \& Gassan, J. (1999). Composites reinforced with cellulose based fibres. Progress in Polymer Science, 24, 2, 221-274.

Boldizar, A., Klason, C., Kubat, J., Naslund, P. \& Saha, P. (1987). Prehydrolyzed Cellulose as Reinforcing Filler for Thermoplastics. International Journal of Polymeric Materials, 11, 4, 229-262.

Cavaille, J. Y., Chanzy, H., Fleury, E. \& Sassi, J. F. Surface-modified cellulose microfibrils, method for making same, and use therof as a filler in comopsite materials. WO9712917 1997.

Dalmas, F., Cavaille, J. Y., Gauthier, C., Chazeau, L. \& Dendievel, R. (2007). Viscoelastic behavior and electrical properties of flexible nanofiber filled polymer nanocomposites. Influence of processing conditions. Composites Science and Technology, 67, 5, 829-839.

Dufresne, A. \& Vignon, M. R. (1998). Improvement of starch film performances using cellulose microfibrils. Macromolecules, 31, 8, 2693-2696. 
Eichhorn, S. J. (2006), Useful insights into cellulose nanocomposites using Raman spectroscopy, In: Cellulose Nanocomposites: Processing, Characterization, and Properties, 63-77,Amer Chemical Soc, 0097-6156, Washington.

Eyholzer, C., Bordeanu, N., Lopez-Suevos, F., Rentsch, D., Zimmermann, T. \& Oksman, K. (2010a). Preparation and characterization of water-redispersible nanofibrillated cellulose in powder form. Cellulose, 17, 1, 19-30.

Eyholzer, C., Lopez-Suevos, F., Tingaut, P., Zimmermann, T. \& Oksman, K. (2010b). Reinforcing effect of carboxymethylated nanofibrillated cellulose powder on hydroxypropyl cellulose. Cellulose, 17, 4, 793-802.

Gardner, D. J., Oporto, G. S., Mills, R. \& Samir, M. (2008). Adhesion and surface issues in cellulose and nanocellulose. Journal of Adhesion Science and Technology, 22, 5-6, 545567.

Garlotta, D. (2001). A literature review of poly(lactic acid). Journal of Polymers and the Environment, 9, 2, 63-84.

Gousse, C., Chanzy, H., Cerrada, M. L. \& Fleury, E. (2004). Surface silylation of cellulose microfibrils: preparation and rheological properties. Polymer, 45, 5, 1569-1575.

Gousse, C., Chanzy, H., Excoffier, G., Soubeyrand, L. \& Fleury, E. (2002). Stable suspensions of partially silylated cellulose whiskers dispersed in organic solvents. Polymer, 43, 9, 2645-2651.

Grunert, M. \& Winter, W. T. (2002). Cellulose nanocrystal reinforced cellulose acetate butyrate nanocomposites. Abstracts of Papers of the American Chemical Society, 223, 240-PMSE.

Habibi, Y., Chanzy, H. \& Vignon, M. R. (2006). TEMPO-mediated surface oxidation of cellulose whiskers. Cellulose, 13, 6, 679-687.

Habibi, Y. \& Dufresne, A. (2008). Highly filled bionanocomposites from functionalized polysaccharide nanocrystals. Biomacromolecules, 9, 7, 1974-1980.

Henriksson, M. \& Berglund, L. (2007). Structure and properties of cellulose nanocomposite films containing melamine formaldehyde. Journal of Applied Polymer Science, 106, 4, 2817-2824.

Hubbe, M. A., Rojas, O. J., Lucia, L. A. \& Sain, M. (2008). Cellulosic Nanocomposites: A Review. Bioresources, 3, 3, 929-980.

Ifuku, S., Nogi, M., Abe, K., Handa, K., Nakatsubo, F. \& Yano, H. (2007). Surface modification of bacterial cellulose nanofibers for property enhancement of optically transparent composites: Dependence on acetyl-group DS. Biomacromolecules, 8, 6, 1973-1978.

Iwamoto, S., Nakagaito, A. N. \& Yano, H. (2007). Nano-fibrillation of pulp fibers for the processing of transparent nanocomposites. Applied Physics a-Materials Science $\mathcal{E}$ Processing, 89, 2, 461-466.

Iwatake, A., Nogi, M. \& Yano, H. (2008). Cellulose nanofiber-reinforced polylactic acid. Composites Science and Technology, 68, 9, 2103-2106.

Janardhnan, S. \& Sain, M. (2006). Isolation of cellulose microfibrils - an enzymatic approach. BioResources, 1, 2, 176-188.

Johnson, R. K., Zink-Sharp, A., Renneckar, S. H. \& Glasser, W. G. (2009). A new bio-based nanocomposite: fibrillated TEMPO-oxidized celluloses in hydroxypropylcellulose matrix. Cellulose, 16, 2, 227-238.

Kim, D. Y., Nishiyama, Y. \& Kuga, S. (2002). Surface acetylation of bacterial cellulose. Cellulose, 9, 3-4, 361-367.

Lasseuguette, E., Roux, D. \& Nishiyama, Y. (2008). Rheological properties of microfibrillar suspension of TEMPO-oxidized pulp. Cellulose, 15, 3, 425-433. 
Lu, J., Askeland, P. \& Drzal, L. T. (2008a). Surface modification of microfibrillated cellulose for epoxy composite applications. Polymer, 49, 5, 1285-1296.

Lu, J., Wang, T. \& Drzal, L. T. (2008b). Preparation and properties of microfibrillated cellulose polyvinyl alcohol composite materials. Composites Part A: Applied Science and Manufacturing, 39, 5, 738-746.

Mathew, A. P., Oksman, K. \& Sain, M. (2005). Mechanical properties of biodegradable composites from poly lactic acid (PLA) and microcrystalline cellulose (MCC). Journal of Applied Polymer Science, 97, 5, 2014-2025.

Nair, K. G., Dufresne, A., Gandini, A. \& Belgacem, M. N. (2003). Crab shell chitin whiskers reinforced natural rubber nanocomposites. 3. Effect of chemical modification of chitin whiskers. Biomacromolecules, 4, 6, 1835-1842.

Nakagaito, A. N., Fujimura, A., Sakai, T., Hama, Y. \& Yano, H. (2009). Production of microfibrillated cellulose (MFC)-reinforced polylactic acid (PLA) nanocomposites from sheets obtained by a papermaking-like process. Composites Science and Technology, 69, 7-8, 1293-1297.

Nakagaito, A. N. \& Yano, H. (2004). The effect of morphological changes from pulp fiber towards nano-scale fibrillated cellulose on the mechanical properties of highstrength plant fiber based composites. Applied Physics a-Materials Science $\mathcal{E}$ Processing, 78, 4, 547-552.

Nakagaito, A. N. \& Yano, H. (2005). Novel high-strength biocomposites based on microfibrillated cellulose having nano-order-unit web-like network structure. Applied Physics a-Materials Science E Processing, 80, 1, 155-159.

Nakagaito, A. N. \& Yano, H. (2008). The effect of fiber content on the mechanical and thermal expansion properties of biocomposites based on microfibrillated cellulose. Cellulose, 15, 4, 555-559.

Nogi, M., Ifuku, S., Abe, K., Handa, K., Nakagaito, A. N. \& Yano, H. (2006). Fiber-content dependency of the optical transparency and thermal expansion of bacterial nanofiber reinforced composites. Applied Physics Letters, 88, 13.

Paakko, M., Ankerfors, M., Kosonen, H., Nykanen, A., Ahola, S., Osterberg, M., Ruokolainen, J., Laine, J., Larsson, P. T., Ikkala, O. \& Lindstrom, T. (2007). Enzymatic hydrolysis combined with mechanical shearing and high-pressure homogenization for nanoscale cellulose fibrils and strong gels. Biomacromolecules, 8 , 6, 1934-1941.

Pandey, J. K., Kumar, A. P., Misra, M., Mohanty, A. K., Drzal, L. T. \& Singh, R. P. (2005). Recent advances in biodegradable nanocomposites. Journal of Nanoscience and Nanotechnology, 5, 4, 497-526.

Pizzoli, M., Scandola, M. \& Ceccorulli, G. (1991). Dielectric and mechanical loss processes in hydroxypropylcellulose. Plastics Rubber and Composites Processing and Applications, $16,4,239-244$.

Rials, T. G. \& Glasser, W. G. (1988). Thermal and Dynamic Mechanical-Properties of Hydroxypropyl Cellulose Films. Journal of Applied Polymer Science, 36, 4, 749-758.

Saito, T., Nishiyama, Y., Putaux, J. L., Vignon, M. \& Isogai, A. (2006). Homogeneous suspensions of individualized microfibrils from TEMPO-catalyzed oxidation of native cellulose. Biomacromolecules, 7, 6, 1687-1691.

Samir, M., Alloin, F. \& Dufresne, A. (2005). Review of recent research into cellulosic whiskers, their properties and their application in nanocomposite field. Biomacromolecules, 6, 2, 612-626.

Samir, M., Alloin, F., Paillet, M. \& Dufresne, A. (2004). Tangling effect in fibrillated cellulose reinforced nanocomposites. Macromolecules, 37, 11, 4313-4316. 
Sassi, J. F. \& Chanzy, H. (1995). Ultrastructural Aspects of the Acetylation of Cellulose. Cellulose, 2, 2, 111-127.

Siqueira, G., Bras, J. \& Dufresne, A. (2009). Cellulose Whiskers versus Microfibrils: Influence of the Nature of the Nanoparticle and its Surface Functionalization on the Thermal and Mechanical Properties of Nanocomposites. Biomacromolecules, 10, 2, 425-432.

Siro, I. \& Plackett, D. (2010). Microfibrillated cellulose and new nanocomposite materials: a review. Cellulose, 17, 3, 459-494.

Stenstad, P., Andresen, M., Tanem, B. S. \& Stenius, P. (2008). Chemical surface modifications of microfibrillated cellulose. Cellulose, 15, 1, 35-45.

Suryanegara, L., Nakagaito, A. N. \& Yano, H. (2009). The effect of crystallization of PLA on the thermal and mechanical properties of microfibrillated cellulose-reinforced PLA composites. Composites Science and Technology, 69, 7-8, 1187-1192.

Tingaut, P., Zimmermann, T. \& Lopez-Suevos, F. (2010). Synthesis and Characterization of Bionanocomposites with Tunable Properties from Poly(lactic acid) and Acetylated Microfibrillated Cellulose. Biomacromolecules, 11, 2, 454-464.

Turbak, A. F., Snyder, F. W. \& Sandberg, K. R. (1983). Microfibrillated Cellulose, A New Cellulose Product: Properties, Uses and Commercial Potential. Journal of Applied Polymer Science: Applied Polymer Symposium, 37, 815-827.

Werbowyj, R. S. \& Gray, D. G. (1976). Liquide crystalline structure in aqueous hydroxypropylcellulose solutions. Molecular Crystals and Liquid Crystals, 34, 4, 97103.

Werbowyj, R. S. \& Gray, D. G. (1980). Ordered phase formation in concentrated hydroxypropylcellulose solutions. Macromolecules, 13, 1, 69-73.

Wojciechowski, P. (2000). Thermotropic mesomorphism of selected (2hydroxypropyl)cellulose derivatives. Journal of Applied Polymer Science, 76, 6, 837844.

Zimmermann, T., Pöhler, E. \& Geiger, T. (2004). Cellulose fibrils for polymer reinforcement. Advanced Engineering Materials, 6, 9, 754-761.

Zimmermann, T., Pöhler, E. \& Schwaller, P. (2005). Mechanical and morphological properties of cellulose fibril reinforced nanocomposites. Advanced Engineering Materials, 7, 12, 1156-1161. 


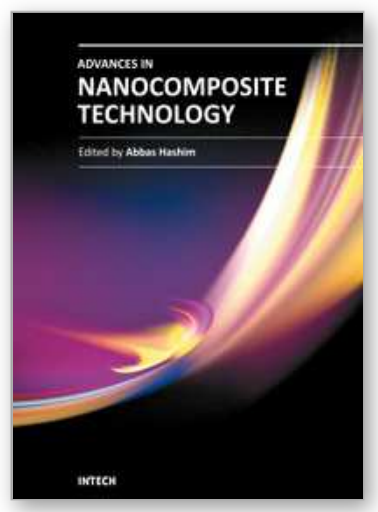

\author{
Advances in Nanocomposite Technology \\ Edited by Dr. Abbass Hashim
}

ISBN 978-953-307-347-7

Hard cover, 374 pages

Publisher InTech

Published online 27, July, 2011

Published in print edition July, 2011

The book â€œAdvances in Nanocomposite Technologyâ€ contains 16 chapters divided in three sections. Section one, â€œElectronic Applicationsâ€, deals with the preparation and characterization of nanocomposite materials for electronic applications and studies. In section two, â€œMaterial Nanocompositesâ€, the advanced research of polymer nanocomposite material and polymer-clay, ceramic, silicate glass-based nanocomposite and the functionality of graphene nanocomposites is presented. The â€œHuman and Bioapplicationsâ€ section is describing how nanostructures are synthesized and draw attention on wide variety of nanostructures available for biological research and treatment applications. We believe that this book offers broad examples of existing developments in nanocomposite technology research and an excellent introduction to nanoelectronics, nanomaterial applications and bionanocomposites.

\title{
How to reference
}

In order to correctly reference this scholarly work, feel free to copy and paste the following:

Philippe Tingaut, Christian Eyholzer and Tanja Zimmermann (2011). Functional Polymer Nanocomposite Materials from Microfibrillated Cellulose, Advances in Nanocomposite Technology, Dr. Abbass Hashim (Ed.), ISBN: 978-953-307-347-7, InTech, Available from: http://www.intechopen.com/books/advances-innanocomposite-technology/functional-polymer-nanocomposite-materials-from-microfibrillated-cellulose

\section{INTECH}

open science | open minds

\author{
InTech Europe \\ University Campus STeP Ri \\ Slavka Krautzeka 83/A \\ 51000 Rijeka, Croatia \\ Phone: +385 (51) 770447 \\ Fax: +385 (51) 686166 \\ www.intechopen.com
}

\author{
InTech China \\ Unit 405, Office Block, Hotel Equatorial Shanghai \\ No.65, Yan An Road (West), Shanghai, 200040, China \\ 中国上海市延安西路65号上海国际贵都大饭店办公楼 405 单元 \\ Phone: +86-21-62489820 \\ Fax: +86-21-62489821
}


(C) 2011 The Author(s). Licensee IntechOpen. This chapter is distributed under the terms of the Creative Commons Attribution-NonCommercialShareAlike-3.0 License, which permits use, distribution and reproduction for non-commercial purposes, provided the original is properly cited and derivative works building on this content are distributed under the same license. 